\title{
ALGUNS EFEITOS DO FLUOMETURON SOBRE O CRESCIMENTO INICIAL DE Bidens pilosa $\mathrm{L}$.
}

\author{
G. DE MARINIS*, W.B.C. DELITTI**, \\ A.A.A. FERREIRA** \& R.F. DOS SANTOS** \\ * Professor Titular, Instituto de Biociências da \\ UNESP, Rio Claro, SP. \\ ** Aluno do curso de Pós-graduação em Botânica, \\ Instituto de Biociências da USPP, São Paulo, \\ SP. \\ Recebido para publicação em 05.11.79.
}

\section{RESUMO}

Sementes de picão-preto (Bidens pilosa L.) foram germinadas em placas de petri sobre papel de filtro molhado com diferentes concentrações de fluometuron $(0,5,25,125$ e $625 \mathrm{ppm})$. O ensaio foi conduzido em condições de laboratório, com variação de temperatura entre $24^{\circ} \mathrm{C}$ e $28^{\circ} \mathrm{C}$ e intensidade luminosa máxima de 600 lux e foi encerrado após sete dias (168 horas). O fluometuron diminuiu a germinabilidade e o comprimento da radídula e do hipocótilo, afetou o formato dos cotilédones e, nas concentrações mais elevadas, impediu a rejeição do pericarpo. Os efeitos observados não são atribuíveis a lesões bioquímicas do processo fotossintético.

UNITERMOS: Herbicidas, fluometuron, $\mathrm{Bi}$ bens pilosa L., germinação.

\section{SUMMARY}

SOME EFFECTS OF FLUOMETURON ON

\section{EARLY GROWTH OF Bidens pilosa L.}

Seeds of Bidens pilosa L. (Compositae) were germinated in Petri dishes on filter paper wetted with aqueous suspensions of fluometuron at different concentrations $(0,5,25,125$ and $625 \mathrm{ppm})$. The experiment was conducted during 7 days, under room conditions; the temperature range was $24^{\circ} \mathrm{C}-28^{\circ} \mathrm{C}$ and the maximum light intensity was 600 lux. Fluometuron reduced germination percentage, radicle and hypocotyl lenght, affected cotyledon shape and, at the higher concentrations, prevented the pericarp rejection. The observed effects can not be attributed to biochemical lesions of the photosynthetic process.

KEYWORDS: Herbicides, fluometuron, $B i$ dens pilosa L., germination.

\section{INTRODUÇÃO}

O estudo dos efeitos das uréias substituídas sobre o crescimento inicial de Bidens pilosa $\mathrm{L}$. foi iniciado por De Marins e Absy (8) utilizando o chlorbromuron. O presente trabalho visa fornecer alguns dados básicos para a melhor compreensão da sensibilidade dos processos iniciais de crescimento desta espécie a outro herbicida do mesmo grupo, o fluometuron [N - (3-trifluorometil fenil) - N,N - dimetil - uréia]. Este herbicida é recomendado por Forster e Alves (9) para a cultura do algodão, bananeira, café, chá preto, citros e mandioca. Segundo Hertwig (11) é especialmente indicado para a cultura do algodão devido a seu elevado grau de seletividade. De acordo com Moreland e Hilton (15) o fluometuron é absorvido principalmente pelas raízes e possui, no solo, uma meia-vida de cerca de 60 dias. Inibe o desenvolvimento dos cloroplastos e a biossíntese dos carotenóides, influindo sobre o transporte de elétrons na reação de Hill e deprimindo, portanto, a fotossíntese (Van Oorschot, 19).

Entre as numerosas espécies controladas pelo fluometuron encontra-se o picão-preto (Bidens pilosa L.) pertencente à famlfia Compositae, subfamflia Asteroideae, tribo Helianthease, subtribo Coreopsidinae, cosmopolita tropical das mais importantes (Wagenitz, 20) e incluída entre as piores malerbas do mundo por Holm et al. (12). Já foi mencionada no Brasil por inúmeros autores, entre os quais Cardenas e Coulston (3), De Marins (6) e Blanco (1), sendo consi- 
derada altamente nociva. Trata-se de uma planta herbácea anual (terófita) com ciclo biológico de duração variável entre 60 e 90 dias (Leitão F. ${ }^{\circ}$ et al. 14) ou entre 150 e 360 dias (Tamashiro e Leitão F. $\left.{ }^{\circ}, 18\right)$. Embora possua a capacidade de se propagar vegetativamente (Hadac \& Hadacova, 10) a espécie se reproduz normalmente através de seus aquênios, que lhe asseguram uma capacidade reprodutiva elevada (De Marinis, 7; Schwerzel, 17). Os aquênios foram descritos, entre outros, por Pancho e Guantes (16) e por Leitão $F$. $^{\circ}$ et al. (14) e pertencem, do ponto de vista ecomorfológico, ao tipo desmócoro de Dansereau e Lems (Dansereau, 5). Alguns efeitos da temperatura sobre a germinacão desta espécie foram estudados por Kirszenzaft e Felippe (13).

\section{MATERIAIS E MÉTODOS}

O produto utilizado neste ensaio continha fluometuron pó molhável a $80 \%$ de i.a. (*). Foram empregadas as seguintes concentrações: 0 ppm (= T), 5 ppm, 25 ppm, 125 ppm e 625 ppm de i.a..

Aquênios de Bidens pilosa L. coletados no Horto Florestal «Navarro de Andrade», Rio Claro, foram colocados em placas de petri (30 aquênios por placa) forradas com papel de filtro e contendo, cada uma, $30 \mathrm{ml}$ da respectiva suspensão. As placas foram vedadas com fita adesiva e mantidas durante uma semana (168 horas) em condições de laboratório, com luminosidade até 600 lux e temperatura entre $24^{\circ} \mathrm{C}$ e $28^{\circ} \mathrm{C}$. Estas condições concordam com as indicações de Kirszenzaft e Felippe (12) que consideram como mais adequadas para a germinação de $B$. pilosa as faixas de $25^{\circ} \mathrm{C}-30^{\circ} \mathrm{C}$ no claro e de $20^{\circ} \mathrm{C}-25^{\circ} \mathrm{C}$ no escuro.

Para cada tratamento foram considerados os seguintes parâmetros:

$\begin{array}{ll}\mathbf{G} \% & =\text { Percentagem de germinaçāo } \\ \mathbf{R} & =\text { Comprimento da radícula }(\mathrm{mm}) \\ \mathbf{H} & =\text { Comprimento do hipocótilo }(\mathrm{mm}) \\ \mathbf{H} / \mathbf{R} & =\text { Relação entre os comprimentos } \\ & \text { do hipocótilo e da radícula } \\ \mathbf{C} & =\text { Comprimento do cotilédone }(\mathrm{mm}) \\ \mathrm{L} & =\text { Largura do cotilédone }(\mathrm{mm}) \\ \frac{\mathrm{L} \times 100}{\mathbf{C}} & =\text { Índice de largura cotiledonar } \\ \mathrm{P} \% & =\begin{array}{l}\text { Percentagem de plântulas que re- } \\ \text { tiveram o pericarpo. }\end{array}\end{array}$ pelos métodos usuais. Considerando que o comprimento do hipocótilo revelou-se, entre os parâmetros estudados, o mais sensível às altas concentrações de fluometuron, achou-se oportuno calcular a curva matemática correspondente aos valores observados para este parâmetro.

(*) Herbicida Cotoran.

\section{RESULTADOS E DISCUSSÃO}

Os resultados do ensaio estão apresentados no Quadro 1 e a variação dos comprimentos da radícula e do hipocótilo na Figura 1.

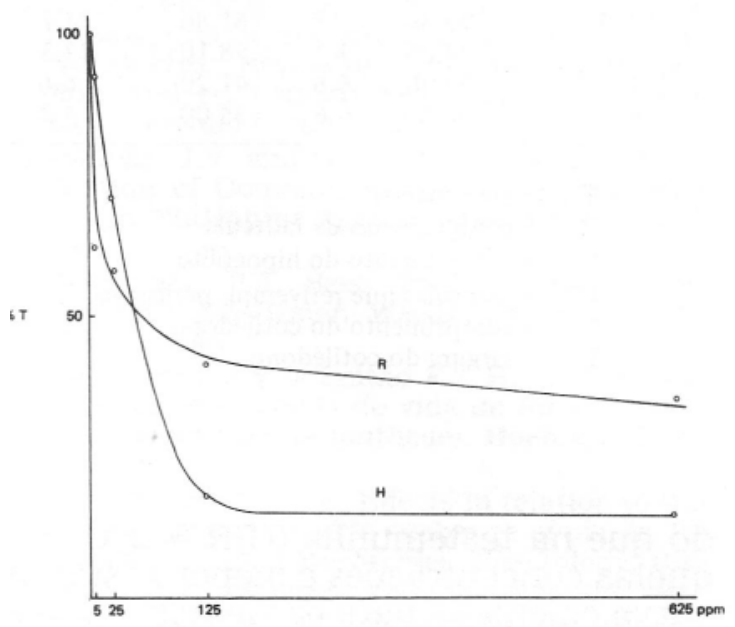

Figura 1- Efeito de fluometuron sobre o comprimento da radícula e do hipocótilo de Bidens pilosa $\mathbf{L}$.

O fluometuron afetou mais ou menos acentuadamente todos os parâmetros estudados.

No que se refere à germinabilidade $(\mathrm{G} \%)$, a resposta foi gradativa e o I50 ficou além dos $625 \mathrm{ppm}$, sugerindo que a presença no solo de fluometuron nas concentrações usuais não chega a afetar o estabelecimento de novas plântulas de $\boldsymbol{B}$. pilosa através da inibição do início do processo germinativo.

Quanto aos parâmetros lineares, o aumento da intensidade de resposta foi maior na faixa entre 25 e $125 \mathrm{ppm}$, faixa esta na qual ficou incluído o Lo para todos estes parâmetros. O considerável efeito da dose mais baixa utilizada $(5 \mathrm{ppm})$ demonstra que o herbicida deve agir visivelmente sobre a plântula e pode portanto ser detectado quando presente no solo em doses bem menores do que $5 \mathrm{ppm}$.

O comprimento da radícula $(\boldsymbol{R})$ reagiu mais intensamente do que o do hipocótilo $(\mathbf{H})$ às concentraçôes mais baixas ( 5 e 25 ppm) e menos do que este às mais altas (125 ppm e 625 ppm). Consequentemente, $o$ indice $\mathbf{H} / \mathbf{R}$ foi maior 
Quadro 1 - Resultados obtidos em plántulas de Bidens pilosa L. aos sete dias, por ação de fluometuron em solução aquosa.

\begin{tabular}{|c|c|c|c|c|c|c|c|c|c|c|}
\hline $\begin{array}{c}\text { Tratamento } \\
\text { ppm }\end{array}$ & $\mathbf{G} \%$ & $\mathbf{R}(\mathrm{mm})$ & $\mathbf{R}(\% \mathrm{de} \mathbf{T})$ & $\mathrm{H}(\mathrm{mm})$ & $\mathbf{H}(\% \mathrm{de} \mathbf{T})$ & $\mathbf{H} / \mathbf{R}$ & $\mathbf{P} \%$ & $\mathrm{C}(\mathrm{mm})$ & $\mathrm{L}(\mathrm{mm})$ & $\frac{L \times 100}{C}$ \\
\hline $\begin{array}{r}0 \\
5 \\
25 \\
125 \\
625\end{array}$ & $\begin{array}{l}90,00 \\
93,30 \\
83,30 \\
70,00 \\
60,00\end{array}$ & $\begin{array}{r}16,0 \\
9,9 \\
9,3 \\
6,6 \\
5,6\end{array}$ & $\begin{array}{r}100,00 \\
61,80 \\
58,10 \\
41,20 \\
35,00\end{array}$ & $\begin{array}{r}37,0 \\
34,1 \\
22,3 \\
6,6 \\
5,3\end{array}$ & $\begin{array}{r}100,00 \\
92,20 \\
70,20 \\
17,80 \\
14,30\end{array}$ & $\begin{array}{l}2,31 \\
3,44 \\
2,40 \\
1,00 \\
0,94\end{array}$ & $\begin{array}{c}0 \\
0 \\
4 \\
100 \\
100\end{array}$ & $\begin{array}{c}5,60 \\
6,74 \\
6,53 \\
- \\
-\end{array}$ & $\begin{array}{c}0,56 \\
0,95 \\
1,03 \\
- \\
-\end{array}$ & $\begin{array}{c}10,00 \\
14,09 \\
15,77 \\
- \\
-\end{array}$ \\
\hline $\begin{array}{l}\mathrm{G} \%= \\
\mathrm{R}= \\
\mathrm{H}= \\
\mathrm{P} \%= \\
\mathrm{C}= \\
\mathrm{L}=\end{array}$ & $\begin{array}{l}=\text { germinaça } \\
=\text { comprime } \\
=\text { comprime } \\
=\text { plântulas } \\
=\text { comprime } \\
=\text { largura do }\end{array}$ & $\begin{array}{l}\text { ão } \\
\text { ento da ra } \\
\text { ento do hi } \\
\text { que retive } \\
\text { ento do cc } \\
\text { o cotilédo }\end{array}$ & $\begin{array}{l}\text { dícula } \\
\text { pocólito } \\
\text { ram pericarp } \\
\text { tilédone } \\
\text { ne }\end{array}$ & & & \multicolumn{5}{|c|}{$\mathrm{T}=$ tratamento testemunha $(0 \mathrm{ppm})$} \\
\hline
\end{tabular}

do que na testemunha $(H / R=2,31)$ naquelas concentrações e menor nestas. A curva calculada para os valores do comprimento do hipocótilo foi uma hipérbole de equação: $\mathrm{x}^{2}+\mathrm{Axy}+\mathrm{By}^{2}+\mathrm{Cx}+$ $\mathrm{Dy}+\mathrm{E}=0$.

O comprimento $(\mathrm{C})$ e a largura (L) do cotilédone se apresentaram maiores do que a testemunha nos tratamentos com 5 e 25 ppm e a largura aumentou, proporcionalmente, mais do que o comprimento, provocando o aumento do índice de largura e afetando, deste modo, o formato do limbo cotiledonar. Nos tratamentos mais fortes (125 e $625 \mathrm{ppm}$ ) estes parâmetros não foram observados por causa da retenção do pericarpo.

Esta retencão $(\mathrm{P} \%)$ apresentou certa variabilidade individual, ficando seu limiar aquém de $25 \mathrm{ppm}$ em alguns casos. Na quase totalidade, entretanto, o limiar ficou além deste valor.

A própria natureza do ensaio aqui relatado exclui a possibilidade de que os efeitos observados (com a possível exceção dos parâmetros cotiledonares) sejam atribuíveis às lesões bioquímicas do processo fotossintético que são consideradas como típicas do fluometuron (Moreland e Hilton, 15; Van Oorschot, 19).E possível que se trate de efeitos inibitórios semelhantes àqueles atribuidos ao monuron por Minshall em 1960 (Brian, 2). De qualquer maneira, os resultados deste ensaio não concordam com a afirmativa de Cartwright (4) se gundo a qual «Ureas ... do not generally affect either germination or seedling es- tablishment».

Os resultados obtidos nas condições deste ensaio sugerem a conveniência de um estudo pormenorizado da resposta da plântula de $\boldsymbol{B}$. pilosa ao fluometuron na faixa 0 - 5 ppm, para verificar os limiares de efeito visível, e na faixa $25-125$, para determinar com precisão os respectivos valores do I50. Sugerem também a conveniência de investigar se pelo menos alguns desses efeitos poderiam ser devidos a uma ação semelhante à das citocininas como a que já foi verificada em numerosos derivados da uréia.

\section{AGRADECIMENTOS}

Ao Prof. Dr. Izaías R. Nogueira, da Escola Superior de Agricultura «Luiz de Queiroz., USP, pelo cálculo da curva matemática referente aos valores do comprimento do hipocótilo.

\section{LITERATURA CITADA}

1. Blanco, H.G. Catálogo das espécies de mato infestantes de areas cultivadas no Brasil. Família do picão-preto (Compositae). O Biológico, 42(3/4): 62-97, 1976.

2. Brian, R.C. The history and classification of herbicides. In: Audus, J.L. (ed.) Herbicides. Physiology, Biochemistry, Ecology, 2nd. ed. London, New York, San Francisco, Academic Press, 1976.

3. Cardenas, J. and Coulston, L. Weeds of Brazil. A List of Common and Scientific Names. Oregon State University, Corvallis, 1967. 
4. Cartwright, P.M. General growth response of plants. In: Audus, J.L. (ed.) Herbicides. Physiology, Biochemistry, Ecology, 2nd. ed. London, New York, San Francisco, Academic Press, 1976.

5. Dansereau, P. Biogeography. An Ecological Perspective. New York, The Ronald Press Company, 1957.

6. De Marinis, G. Catálogo brasileiro de plantas daninhas da família Compositae: 2.a parte. Ciência e Cultura, 25(6, supl.): 521, 1973.

7. De Marinis, G. Nota sobre a capacidade reprodutiva de Bidens pilosa L. Revista de Agricultura, 48(2/3): 95-100, 1973.

8. De Marinis, G. e Absy, M.L. Alguns efeitos do chlorbromuron sobre a germinação de Bidens pilosa L. Ciência e Cultura, 29 (7, supl.): 18, 1977.

9. Forster, R. e Alves, A. Herbicidas. Eliminação correta das ervas daninhas. Separata de A Granja, 351: 1-38, 1977.

10. Hadac, E. and Hadacova, V. Notes on the ecology and distribution of Bidens pilosa L. in Cuba. Folia geobot. phytotax. Praha, 4: $165173,1969$.

11. Hertwig, K. von. Manual de herbicidas, desfolhantes, dessecantes e fitorreguladores. São Paulo, Editora Agronômica Ceres, 1977.

12. Holm, L.G.; Plucknett, D.L.; Pancho, J.V. and Herberger, J.P. The World's Worst Weeds. Distribution and Biology. Honolulu, University Press of Hawaii, 1977.
13. Kirszenzaft, S.L. e Felippe, G.M. Germinação da unidade de dispersão de Bidens pilosa L. Congresso Nacional de Botânica, $28 .^{\circ}$, Belo Horizonte, 1977. Resumos, p.III-10.

14. Leitão F. ${ }^{\circ}$, H. -de F.; Aranha, C. e Bacchi, O. Plantas invasoras de culturas no Estado de São Paulo, Vol. II, São Paulo, Hucitec, 1975.

15. Moreland, D.E. and Hilton, J.L. Actions on photosynthetic systems. In: Audus, J.L. (ed.) Herbicides. Physiology, Biochemistry, Ecology. 2nd. ed. London, New York, San Francisco, Academic Press, 1976.

16. Pancho, J.V. and Guantes, M.M. Seed Identification of Common Weeds in Lowland, Rice Fields. Philippine Agriculturist, 46(7): 481-513, 1962.

17. Schwerzel, P.J. Seed Production of Some Common Rhodesian Weeds. PANS(C), 13(3): 215-217, 1967.

18. Tamashiro, J.Y. e Leitão F. ${ }^{\circ}, H$. de F. Observações sobre o ciclo de vida de Bidens pilosa L. (Compositae-Heliantheae). Hoehnea, 7: 2740, 1978.

19. Van Oorschot, J.L.P. Effects in relation to water and carbon dioxide exchange of plants. In: Audus, J.L. (ed.) Herbicides. Physiology, Biochemistry, Ecology. 2nd. ed. London, New York, San Francisco, Academic Press, 1976.

20. Wagentz, G. Campanulales. In A Engler's Syllabus der Pflanzenfamilien, zwõlfte Aufl. II Band, Berlin-Nikolassee, Gebruder Borntraeger, 1964. 